\title{
Characterization of a Calcium Current in a Vertebrate Cholinergic Presynaptic Nerve Terminal
}

\author{
E. F. Stanley ${ }^{1}$ and G. Goping ${ }^{2}$ \\ ${ }^{1}$ NINDS Biophysics Laboratory and ${ }^{2}$ NIDDK Laboratory of Cell Biology and Genetics, National Institutes of Health, \\ Bethesda, Maryland 20892
}

\begin{abstract}
Calcium currents were recorded from a cholinergic presynaptic nerve terminal in the chick ciliary ganglion using the whole-cell voltage-clamp technique. The presynaptic element of this synapse is in the form of a calyx that envelops the postsynaptic ciliary neuron. A method was developed to isolate the ciliary neuron, expose the calyx, and apply patchclamp electrodes under visual control. The presynaptic $\mathrm{Ca}$ current activated at $+30 \mathrm{mV}$ with a fast time constant of about $1.5 \mathrm{msec}$ and deactivated at $-80 \mathrm{mV}$ with a time constant of about $0.5 \mathrm{msec}$, values that are consistent with a role in action-potential-dependent transmitter release. The calyx Ca current was blocked by $0.1 \mathrm{mM} \mathrm{Cd}$ or $2 \mu \mathrm{M} \omega$-conotoxin and was resistant to voltage-dependent inactivation. The presynaptic $\mathrm{Ca}$ channel exhibits similarities to the $\mathrm{N}$-type group but differs from these by the minimal voltage-dependent inactivation. This type of channel, designated $\mathrm{Ca}_{\mathrm{N}-\mathrm{PT}}(\mathrm{N}$ like, presynaptic terminal), may play a key role in transmitter release at many vertebrate fast-transmitting synapses.
\end{abstract}

Calcium influx is a prerequisite for the impulse-dependent release of transmitter from neurons. However, the characterization of Ca channels in vertebrate presynaptic nerve terminals has been hampered by the lack of suitable experimental models. A major difficulty is the small size and general inaccessibility of these structures, which has precluded the use of voltage-clamp techniques. The study of presynaptic Ca channels has therefore relied on more indirect approaches, such as inferences from the action of pharmacological agents on neurosecretion. We have recently developed a technique that allows the direct recording of inward Ca currents $\left(I_{\mathrm{Ca}}\right)$ from a vertebrate presynaptic nerve terminal (Stanley, 1989; Stanley and Goping, 1989) using the calyx synapse of the chick ciliary ganglion. At present, this is the only vertebrate presynaptic nerve terminal that can be voltage clamped under visual control.

The calyx synapse has a simple organization, with a single presynaptic input. Axons from neurons in the Erdinger-Westfal $(\mathrm{E}-\mathrm{W})$ nucleus in the midbrain enter the ciliary ganglion and synapse on the large neurons that innervate the ciliary muscles of the eye (Lyman and Mugnaini, 1980). The E-W axons form a sheetlike terminal, termed a calyx, over a large area of the ciliary neuron surface (Carpenter, 1911; de Lorenzo, 1960; Szen-

\footnotetext{
Received June 28, 1990; revised Nov. 16, 1990; accepted Nov. 19, 1990.

We thank Drs. G. Ehrenstein, G. Barker, E. Rojas, and P. Huddie for reading the manuscript and Dr. S. J.-H. Cheng for comments on the electron micrographs.

Correspondence should be addressed to E. F. Stanley, NINDS Biophysics Laboratory, Building 9, Room 1E124, NIH, Bethesda, MD 20892.

Copyright (C) 1991 Society for Neuroscience $0270-6474 / 91 / 110985-09 \$ 03.00 / 0$
}

tagothai, 1964; Hess, 1965; Hess et al., 1969). Apart from its extensive size, the calyx is essentially a typical fast-transmitting cholinergic presynaptic nerve terminal, containing small, clear synaptic vesicles. Martin and Pilar (1963a,b) demonstrated that it was possible to record action potentials directly from the presynaptic calyx by the blind insertion of microelectrodes into the ganglion (see also Dryer and Chiappinelli, 1985).

The object of the present report is to describe the technique that has been developed to apply patch clamp methods to the calyces and to examine some of the properties of the presynaptic $I_{\mathrm{Ca}}$. The technique is discussed in some detail because it may prove useful in a variety of studies on vertebrate nerve terminals and as a model in the enzymatic dissection of a neural capsule (a neuron plus overlying nerve terminals and Schwann cells). The recording of calyx $I_{\mathrm{Ca}} \mathrm{s}$ required the following steps: dissociation of the ganglion into individual neural capsules, removal of the Schwann cells from the capsule, application of patch electrodes to the exposed calyces, and finally, identification of the $I_{\mathrm{Ca}}$.

\section{Materials and Methods}

Anterograde Lucifer yellow fill of calyces. Lucifer dye (Stewart, 1981) fill of the ganglia through the oculomotor nerve was carried out as described previously (Stanley, 1987), with a few changes. The oculomotor nerve was sucked into a thin-tipped Pasteur pipette that was filled with 5\% Lucifer- $\mathrm{CH}$ (Aldrich) solution dissolved in $0.1 \mathrm{M} \mathrm{LiCl}$ and was left for 2-3 $\mathrm{hr}$ for the dye to diffuse down the axons to the calyces.

Preparation of ciliary ganglia for dissociation. Fifteen-day chick embryos were staged by the length of the middle digit, according to the scheme of Hamburger and Hamilton (1951). The chicks were decapitated, and both ciliary ganglia were removed and placed in a standard culture medium (modified Eagle's medium, with $3.2 \mathrm{gm} /$ liter $\mathrm{HCO}_{3}{ }^{-}$). The ganglia were cleaned, "nicked" with a fine needle to ensure access of the enzymes to the neurons, and incubated at $37^{\circ} \mathrm{C}$ under $8 \% \mathrm{CO}_{2}$ in an enzyme solution consisting of $0.4 \mathrm{mg} / \mathrm{ml}$ collagenase (Worthington, type 4), $0.25 \mathrm{mg} / \mathrm{ml}$ trypsin inhibitor (Sigma soybean), and 10,000 $\mathrm{U} / \mathrm{ml}$ hyaluronidase (HSEP, Worthington) for 60-80 min. At this time, $10 \mathrm{mg} / \mathrm{ml}$ Dispase (Boeringer-Mannheim; $0.5 \mathrm{U} / \mathrm{mg}$ ), a neutral protease, was added, and the ganglia were incubated for an additional 30$35 \mathrm{~min}$.

The ganglia were triturated gently 4-6 times in $50 \mu$ l external recording medium (see below) through a fine-tipped Pasteur pipette and were plated on the center of a standard, uncoated, 35- $\mathrm{mm}$ culture dish (Costar). The cells were left for $5 \mathrm{~min}$ to adhere before an additional 950 $\mu 1$ of extracellular recording medium was added.

Light microscopy. Visualization of calyces was much easier with Hoffman illumination, which tends to emphasize cell membranes, than with phase-contrast microscopy. Calyces that could be visualized clearly under Hoffman illumination were usually accessible to the patch electrode.

Ultrastructure. Ganglia were fixed overnight in a mixture of $2 \%$ paraformaldehyde and $2 \%$ glutaraldehyde in $0.1 \mathrm{M}$ sodium cacodylate buffer $(\mathrm{pH}, 7.3)$. They were postfixed in $1 \%$ osmium tetroxide and $1 \%$ potassium ferricyanide in $0.1 \mathrm{~m}$ sodium cacodylate with $2 \%$ sucrose. The 
ganglia were embedded in epoxy resin (Araldite), and ultrathin sections were cut and stained in an LKB ultrastainer. The sections were examined at $80 \mathrm{kV}$ in a Philips EM 400 electron microscope.

Patch clamp. Standard patch-clamp techniques were used (Hamill et al., 1981). Patch electrodes were made on a programmable FlamingBrown puller (Sutter Instruments) to a tip diameter of approximately 2 $\mu \mathrm{m}$. The tips were fire polished to an electrode resistance, then filled with intracellular solution (see below), of 12.5-25 M $\Omega$, with most about $15 \mathrm{M} \Omega$.

The cells were bathed with external medium of the following composition (in $\mathrm{mm}$ ): tetraethylammonium chloride (TEA; Baker), 115; glucose, 10; Na-HEPES (Sigma), 10; $\mathrm{CaCl}_{2}, 6$ or $20 ; \mathrm{MgCl}_{2}, 2$; with 0.3 $\mu \mathrm{M}$ tetrodotoxin (TTX; Sigma; $\mathrm{pH}, 7.2$ ). The dish was then transferred to the stage of an inverted microscope (Nikon, Diaphot) with fluorescent illumination. Cells were used within $35 \mathrm{~min}$ of plating.

The patch electrode was filled with an internal medium composed of (mM) $\mathrm{CsCl}$ (ICN), 50; $\mathrm{N}$-methyl-D-glucamine chloride (Sigma), 50; TEA, 20; Cs-HEPES, 10; Cs-BAPTA (Molecular Probes), 10; ATP (Sigma), 2; with $3 \mathrm{mg} / \mathrm{ml}$ Lucifer yellow VS (Aldrich; $\mathrm{pH}, 7.2$, adjusted with $\mathrm{CsOH})$. The osmolarity was matched to the external medium with $1 \mathrm{M}$ glucose. The internal medium was frozen in $0.5-\mathrm{ml}$ aliquots, and the Lucifer dye was added immediately prior to the experiment.

The patch electrode was positioned touching the calyx, and gentle suction was applied. When the tip sealed to the membrane, the electrode capacitance was balanced, and the holding potential was applied. Further suction was given until the intervening membrane ruptured and the dye could be seen to enter the patched structure. The membrane was depolarized with a series of voltage steps to $+30 \mathrm{mV}$ at $0.3 \mathrm{~Hz}$, and ion currents were monitored. The pulses were continued until the inward current stabilized, usually within $30 \mathrm{sec}$, indicating that perfusion of the patched structure was complete. Whole-cell seal resistance was in excess of $1 \mathrm{G} \Omega$.

Pulse generation and recording were carried out using pCLAMP software (Axon Inst.) on a Compaq 380/20E computer with a Labmaster TL-1 interface and Axopatch amplifier (Axon Inst.). Data were filtered at 2 or $5 \mathrm{KHz}$ and were digitized at $50-200 \mu \mathrm{sec} /$ point (see Results). Leak correction was carried out on line using a proportional pulse $(\mathrm{P} / N)$ procedure with positive pulses and $N=10$. The use of the $\mathrm{P} / N$ procedure greatly improved the current resolution and reduced the duration of the recording session. Because the leak-correction pulses immediately preceded the test pulse, the correction factor was always appropriate for the recording conditions at that time. In addition, the $\mathrm{P} / N$ correction replaced the necd for whole-cell capacitance compensation. Data were analyzed with pCLAMP and ASYSTANT (Asyst) software.

All experiments were carried out at room temperature, $22-24^{\circ} \mathrm{C}$.

Dye filling from patch pipettes. The morphology of the patched structure was readily evident from the distribution of the Lucifer yellow dye. There was little if any coupling between the calyx and the ciliary neuron because dye transfer was never observed in over 70 individually filled nerve terminals.

$\omega$-Conotoxin. Synthetic $\omega$-conotoxin GVIA ( $\omega$-CTX; Peninsular Labs.) was stored lyophilized or in $1-\mathrm{mm}, 20-\mu$ aliquots at $-20^{\circ} \mathrm{C}$. The aliquots were defrosted only twice before discarding, and the toxin was used within $3 \mathrm{hr}$ of dilution.

\section{Results}

Enzymatic dissociation of the ciliary ganglia

Dissociation to neuron capsules

A series of enzyme treatments was attempted in order to separate the ganglia into individual cells. The effects of each treatment were monitored by examining the structure of the ciliary neurons by light and electronmicroscopy. The ultrastructure of the normal synapse is shown in Figures $1, A$ and $B$, and $2 A$. The presynaptic axon makes contact with the ciliary neuron and spreads out in a sheet with frequent points of synaptic contact, as indicated by the close apposition of calyx and neuron membranes and the accumulation of synaptic vesicles. A thin Schwann cell sheath, often no more than $50 \mathrm{~nm}$ thick, covers the entire calyx.

Initially the ganglia were dissociated with trypsin, but this treatment broke the calyces into small fragments. Clearly, a less severe approach was required, using enzymes with more specific biochemical targets.

Collagenase (Sigma type II) successfully dissociated the ganglia into single neurons but in the process also removed the calyces. Collagenase is almost invariably contaminated with tryptic activity, and the treatment was repeated with low-trypsin collagenase together with trypsin inhibitor (TI) in the enzyme solution. This combination did not dissociate the ganglia, but there was a discernible effect on the extracellular matrix because the neurons could be teased apart more easily. We found that addition of hyaluronidase to the collagenase/TI mixture successfully dissociated the ganglia into individual intact neural capsules. Under light microscopy the ciliary neurons appeared as round structures, generally without any processes, but with a distinct overlying coat of Schwann cells. There were no obvious enzyme-related changes in the ultrastructure of the neural capsules compared to controls, even after 90 -min incubation in the enzyme solution (Fig. $2 B$ ). The calyces remained well apposed to the neuron membrane, with obvious accumulations of secretory vesicles. However, because the Schwann cell sheath remained attached to the calyces, an additional treatment was required to expose the presynaptic terminals.

\section{Removal of the Schwann cell layer}

The next preparative step required an agent that would remove the Schwann cell layer but leave the calyx intact, that is, differentiate between Schwann cell-to-calyx adhesion and calyx-toneuron adhesion. We found that the neutral protease Dispase exhibited some selectivity. The enzyme was added to the last $30 \mathrm{~min}$ of incubation in the collagenase/TI/hyaluronidase treatment. This technique was not ideal, however, and varied with Dispase batches. If the Dispase was left in too long, the calyces were removed in addition to the Schwann cells, indicating that the 2 attachments differ only in the degree of sensitivity to this enzyme.

Examination of the ultrastructure of the Dispase-treated ganglia demonstrated the action of this enzyme on membrane attachment (Fig. 2C). The outer aspect of the calyx was seen in direct contact with the extracellular space, which was not observed in control or collagenase/hyaluronidase-treated ganglia, consistent with a retraction of the Schwann cell membrane sheath. Furthermore, the basal lamina around the Schwann cells, which could be seen as a fuzzy coat in controls, was either absent or greatly reduced. Calyces remained apposed to the ciliary neurons, but gaps in the attachment were observed. It is likely that these gaps occurred in part as a result of the withdrawal of intervening cell processes, but also due to a direct action of the enzyme on calyx-to-neuron attachment. Such an action might account for the less obvious adhesion plaques and pre- and postsynaptic densities (e.g., Fig. $2 C$ ) in the Dispase-treated ganglia, but this observation was not quantified further. Otherwise, the calyces were structurally intact, with accumulations of secretory vesicles and, unlike the trypsin-treated terminals, with no obvious evidence for degeneration.

The enzyme-treated ganglia were triturated gently, and the cells were observed under the light microscope. The capsules had been removed from the ciliary neurons to varying degrees, ranging from seemingly intact capsules to bare neurons. The presynaptic calyx could be observed clearly under Hoffman illumination in a few neurons. It formed a partial outer ring and was tightly attached to the neuron, so that, but for the intervening membrane, it seemed to be a part of the neuron itself. 


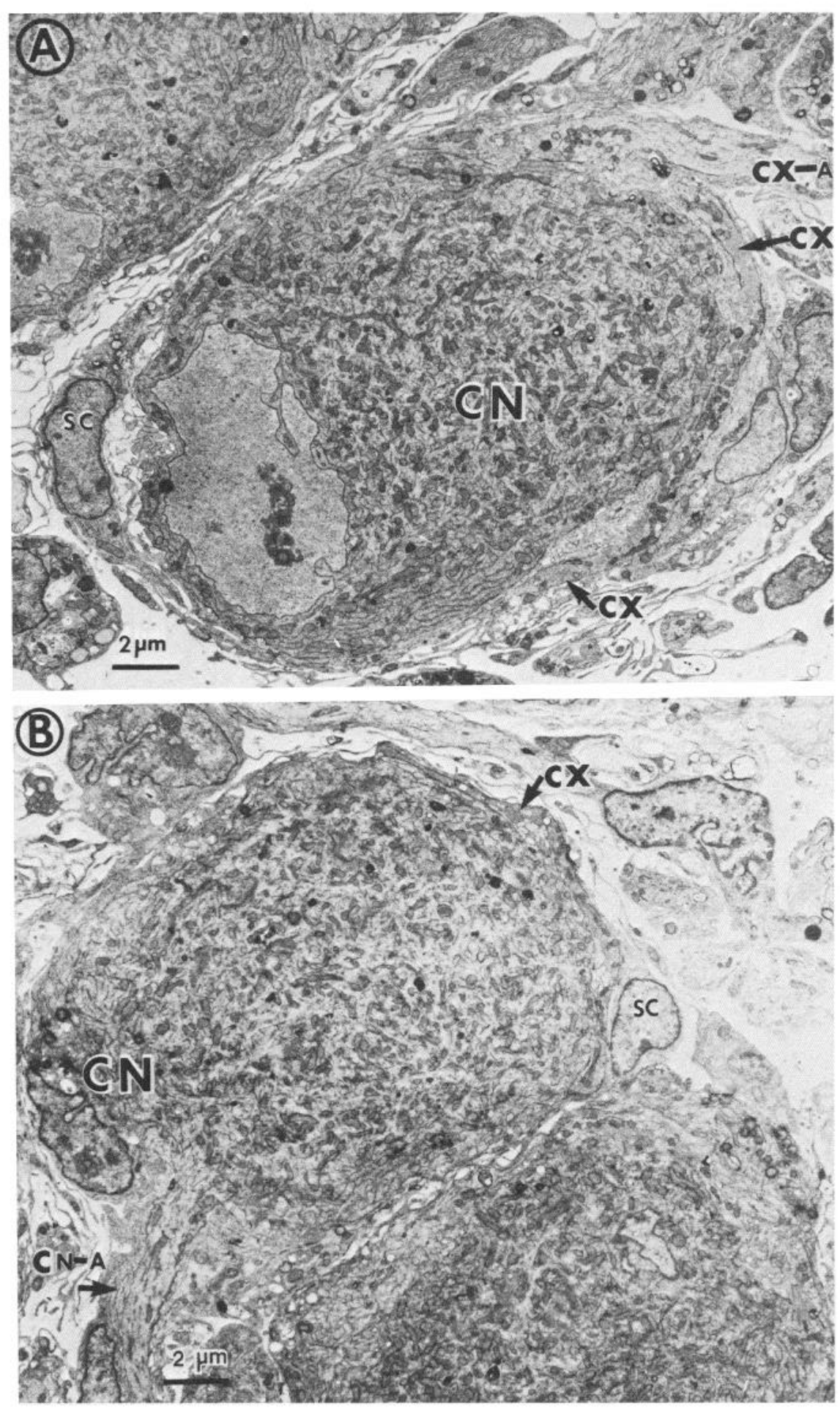

Figure 1. General structure of calyx synapse. $A$, Section through ciliary neuron showing calyx and preterminal axon. The calyx extends continuously from the axon to approximately 6 o'clock on the neuron. $B$, Section through ciliary neuron showing the initial segment. The calyx extends intermittently from 12 to 4 o'clock. $C N$, ciliary neuron; $C X$, calyx; $S C$, Schwann cell; $C X-A$, calyx axon; $C N-A$, ciliary neuron axon.
In addition, the calyx has a characteristic fine-grained texture. In contrast, the glial cells appeared to be clearly distinct from the neuron and had a clear or very coarse texture.

The identification of the calyces was confirmed by Lucifer dye staining. Calyces were first demonstrated by anterograde filling of the oculomotor nerve (Fig. $3 F$; Stanley, 1987). Attempts to dissociate ganglia after staining the calyces met with only limited success because the calyces deteriorated during the initial dye-filling step and much of the stain was lost during the subsequent enzyme treatment and trituration. Nonetheless, residual dye could be seen to remain only in the structures that were closely apposed to the neuron and not in the overlying sheath (data not shown).

The structures associated with the dissociated ciliary neurons were further characterized by filling with Lucifer yellow dye. The dye was dissolved in an intracellular buffer solution and was applied to the neural capsule in a patch pipette. Three main types of structure were observed. The dye-filled ciliary neuron 


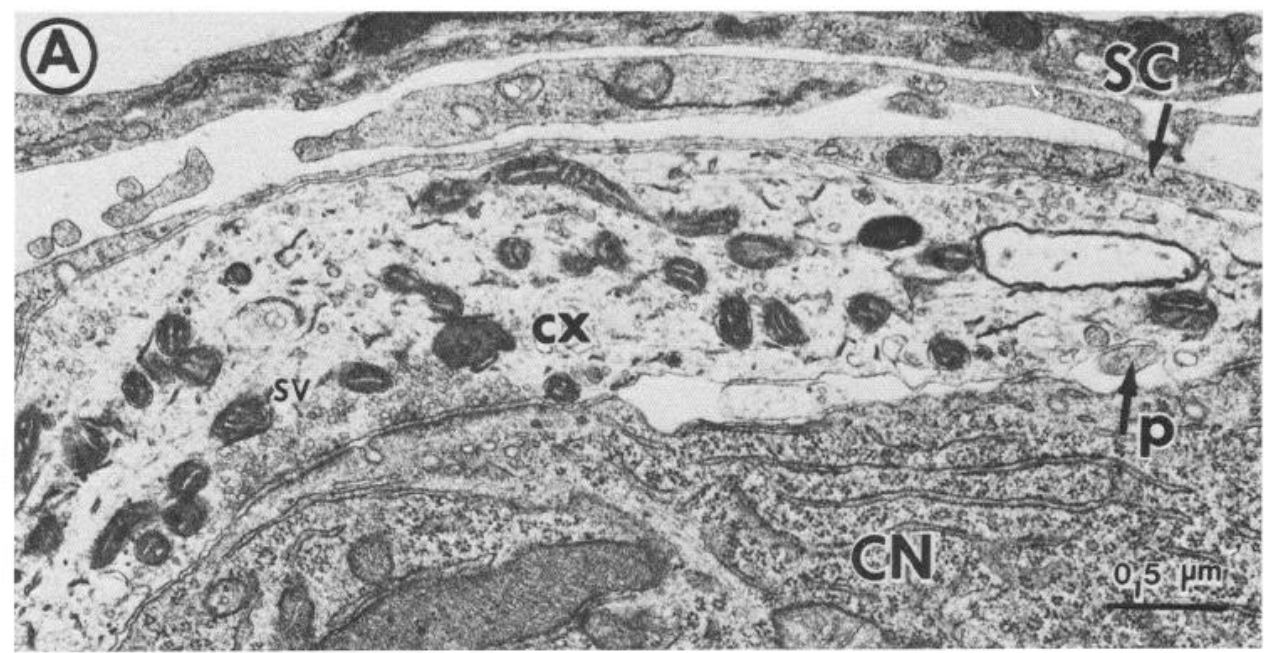

Figure 2. Effect of enzyme treatments on calyx synapse. Each electron micrograph shows a segment of calyx from ciliary neurons that were untreated $(A)$ or treated for $90 \mathrm{~min}$ in collagenase/ hyaluronidase, with $(C)$ or without $(B)$ Dispase during the last $30 \mathrm{~min}$ (see Materials and Methods). Note the very thin, but continuous, covering of the calyx by Schwann cell processes in $A$ and $B$ but the retraction of these in $C$. There are frequent gaps in between the calyx and the ciliary neuron in $C$. Some of these could be due to the direct action of the Dispase, but many appear to be due to the retraction of intervening processes. Such processes are seen in $A$ and $B$ and originate, presumably, from Schwann cells or the neuron itself. $A r$ rowheads, exposed external surface of calyx. $G$, gap between calyx and neuron; $P$, process, or process cluster, in calyx-neuron space; $S V$, synaptic vesicles; $R-S C$, retracting Schwann cell. Other abbreviations are as in Figure 1.
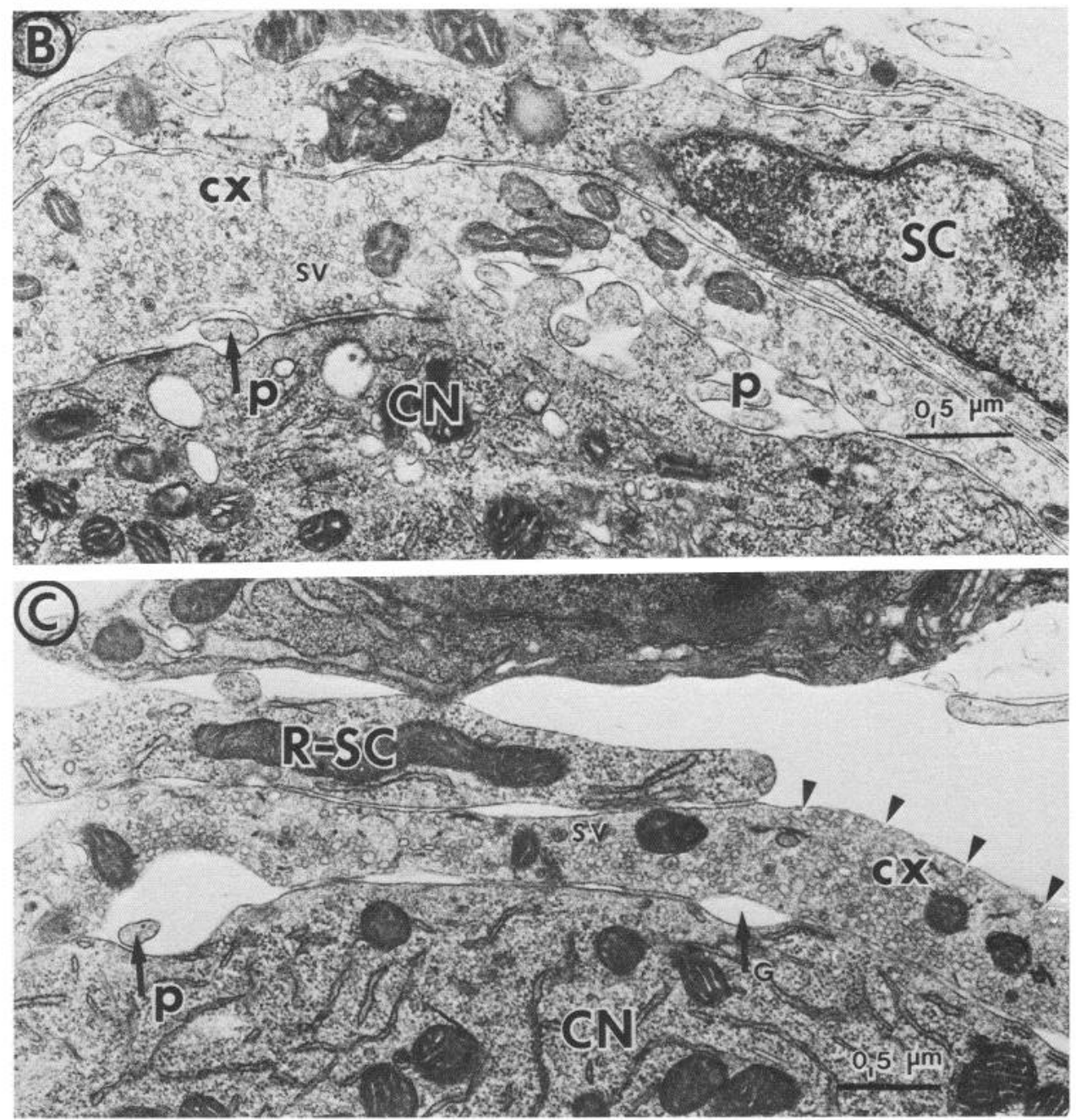

was evident as a large, solid disk or oval (Fig. 3C). Calyces appeared as thin crescents, sometimes extending to completely encircle the neuron (Fig. $3 A, E$ ). These structures were smooth in outline, without any evidence of a nucleus, and were always intimately attached to the neuron surface (see Stanley, 1989). In general, the axon leading to the calyx was severed during dissociation, but in a few dye-filled terminals, a segment of the preterminal axon remained (Fig. $3 D, E$ ). Finally, dye-filled glial cells had definite cell bodies with bulging nuclei and thin, veillike processes (Fig. $3 B$ ). The processes from these cells were unlike the calyces in that the veil could be seen to overlie the calyx and often extended to neighboring cells or formed an attachment to the Petri dish.

Application of the patch electrode to the thicker region of the 


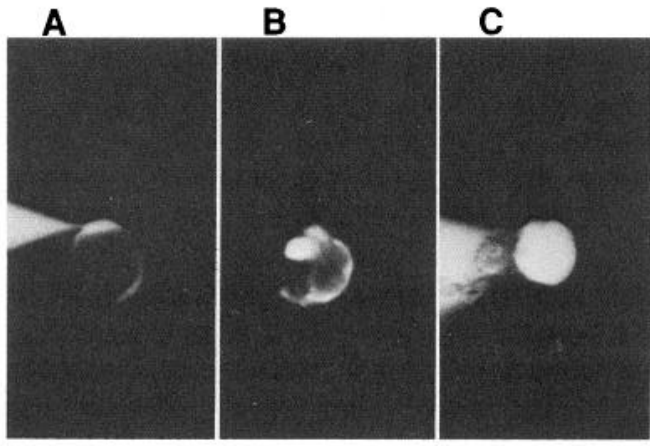

50

$\mu \mathrm{m}$

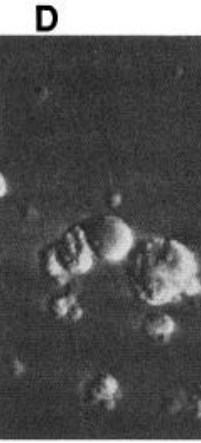

\section{E}

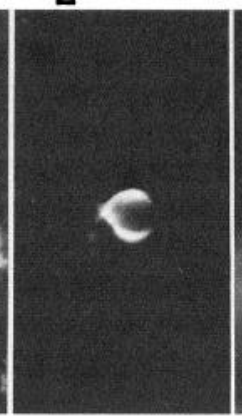

$\mathbf{F}$

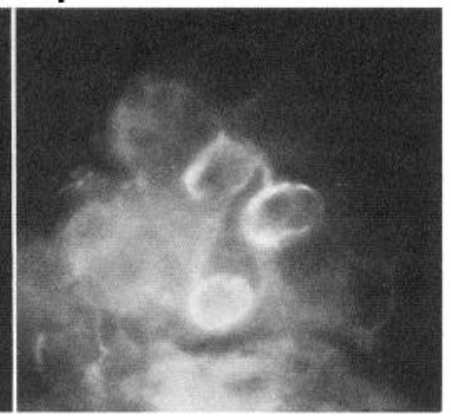

$50 \mu \mathrm{m}$

Figure 3. Light microscopic visualization of ciliary neuron and capsule. Ciliary ganglia were treated as described in Materials and Methods. Cells and cell structures were filled individually by the application of a Lucifer dye-containing patch electrode. $A-C, E$, and $F$ were photographed with fluorescent illumination, and $D$ was photographed under Hoffman illumination. $A$ shows a dye-filled calyx, forming a halo around the cell. A Schwann cell is shown in $B$ with a prominent cell body and a patchy, veil-like process that does not always remain intimately associated with the ciliary neuron. $C$ is a dye-filled ciliary neuron. A rare example of a pre-calyx axon that was retained after trituration and was backfilled with Lucifer is shown in $D$ and $E$. The calyx can be seen distinctly on the upper and lower borders of the ciliary neuron with Hoffman illumination $(D)$, and several areas of stain can be seen along the course of the axon after the calyx was patched. The calyx had deteriorated a little before the fluorescent photograph was taken. $F$ is a teased ganglion after $2 \mathrm{hr}$ of anterograde filling with Lucifer- $\mathrm{CH}$, showing dye-stained calyces. The calyx in best focus, on the right, has an intensely stained, thick region at the point of contact of the presynaptic axon.

calyx resulted in the highest frequency of successful seals. This may be due to purely mechanical reasons in that it is possible to press the electrode tip onto the calyx without rupturing the surface membrane or severely constricting the calyx. The "thick bit" was identified in electron micrographs of intact ganglia as the point at which the E-W neuron makes contact with the ciliary neuron surface (Fig. $1 B$ ), though secondary regions of thickening were also observed.

\section{Calcium currents}

\section{Experimental limitations}

There were 2 main practical difficulties in the recording of ion currents with this preparation. First, the success rate of finding patchable calyces was low. The dissociation took about $2 \mathrm{hr}$, and the cells were only viable (in our solutions) for about 30 min, and accessible calyces were difficult to find, requiring a
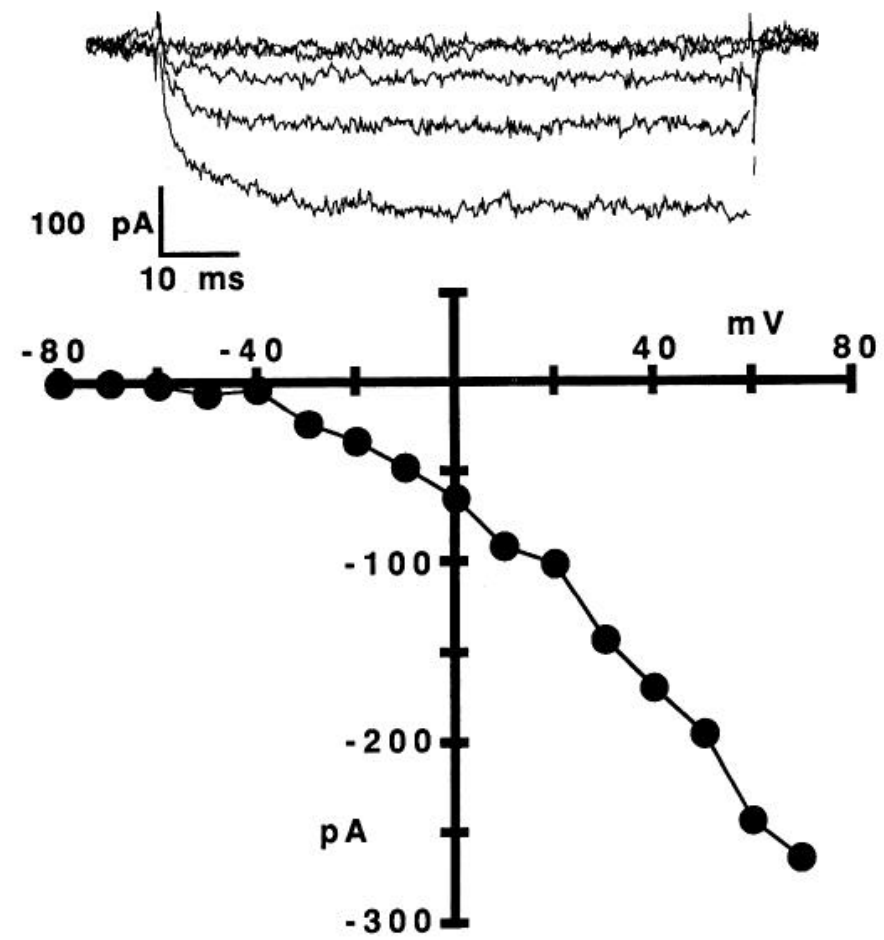

Figure 4. Calyx $I / V$ relation of inward $I_{\mathrm{Ca}}$. Top, sample current traces in a calyx held at $-80 \mathrm{mV}$ and stepped to $-80,-50,-20,+10$, and $+40 \mathrm{mV}$. Bottom, $I / V$ relation in $10-\mathrm{mV}$ steps. Data were filtered at 2 $\mathrm{KHz}$ and sampled at $0.2 \mathrm{msec} /$ point. Current amplitudes were measured over the last $5 \mathrm{msec}$ of each pulse.

trained eye and much patience. Second, seals formed readily on the calyx membrane but could not be maintained for long recording periods, frequently for only 2-3 min. It was important, therefore, to design experiments that did not necessitate long or involved stimulus paradigms.

\section{Current-voltage relation}

It was noted previously that the interpretation of calyx ion currents is complicated by space-clamp problems resulting from the parallel-sheet-like structure of this nerve terminal (Stanley, 1989). As the command-pulse amplitude is depolarized further from the initial $I_{\mathrm{Ca}}$ threshold, Ca channels are recruited from a progressively larger fraction of the nerve terminal. This conclusion is indicated by a current-voltage relation that does not exhibit a typical negative peak, as is observed for $I_{\mathrm{Ca}} \mathrm{s}$ in most cells, but instead increases monotonically with pulse amplitude (Fig. 4). Thus, an $I_{\mathrm{Ca}}$ evoked by a pulse to a command potential, $V_{C}$, reflects ion flow through ion channels at membrane potentials that range from $V_{C}$, for channels close to the electrode, down to channel threshold, for more remote channels. The nonuniform space clamp precludes the biophysical analysis of this current with Hodgkin-Huxley-type kinetics. Upper limits can be obtained, however, to calyx $\mathrm{Ca}$ channel activation and deactivation rates. In addition, the preparation can be used to examine presynaptic $\mathrm{Ca}$ channel inactivation and the sensitivity of these channels to pharmacological agents.

\section{$\mathrm{I}_{C a}$ activation and deactivation}

Successful seals and whole-cell mode $I_{\mathrm{Ca}}$ recordings were most easily obtained when the electrode tip was located on the central thick portion of the calyx. The current traces exhibited a char- 

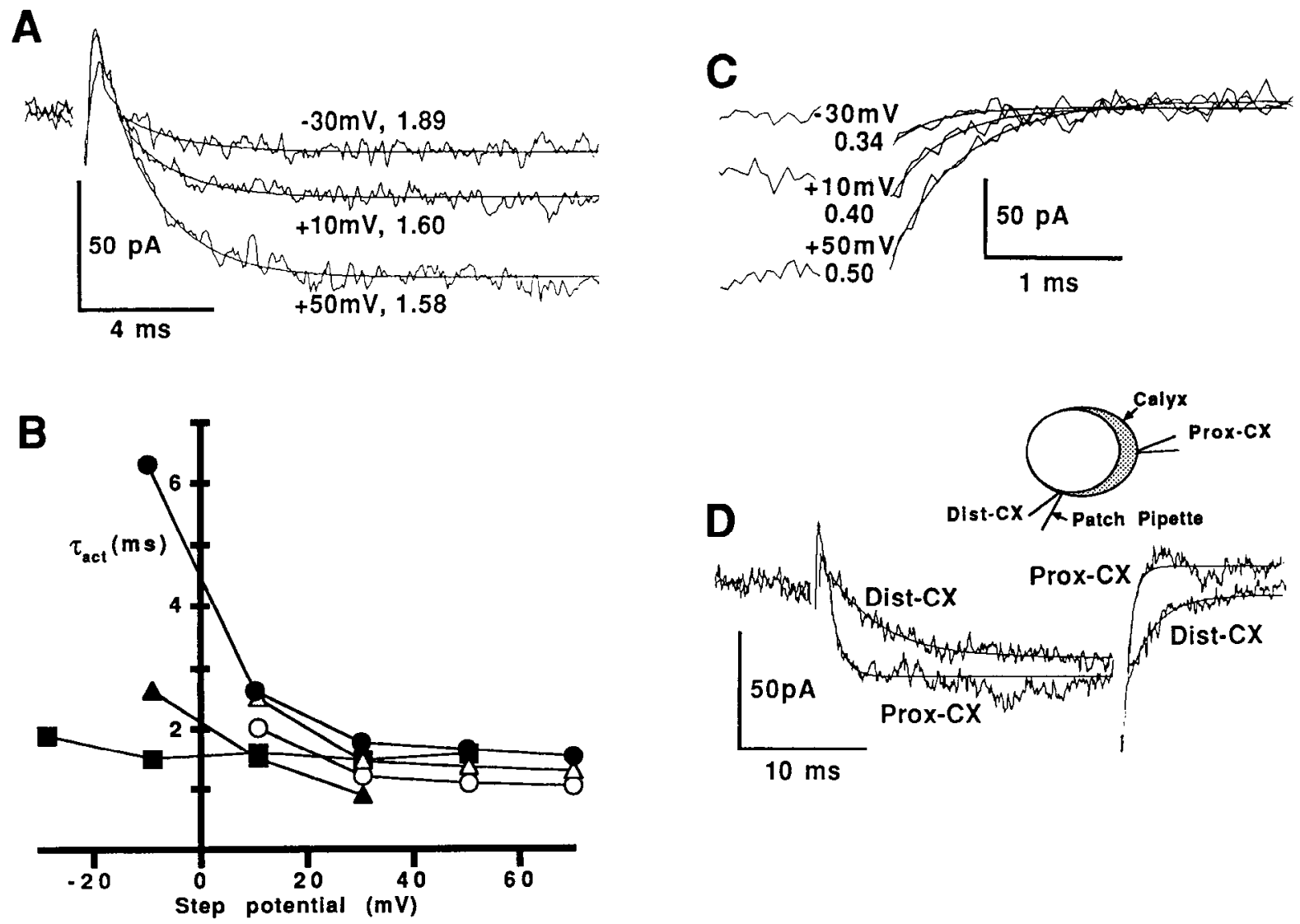

Figure 5. Activation and deactivation of calyx $I_{\mathrm{Ca}} . A$, Single exponential fits to the onset of inward current traces stepped from a $-80 \mathrm{mV}$ holding potential (solid squares in $B$ ). $B$, Plot of $\tau_{\text {act }}$ against step potential for 5 calyces. $C$, Tail currents recorded in 1 calyx on return to a $-80 \mathrm{mV}$ holding potential with superimposed single exponential fits. Voltage-pulse amplitude and $\tau_{\text {dact }}$ are given for each tail. There was no correlation between step potential and current decay rates. $D$, Current traces compared for recordings from the central, thick portion of the calyx (Prox-CX; see inset) and the thin outer skirt (Dist-CX) in 2 different calyces, with a step to $+30 \mathrm{mV}$ from a holding potential of $-80 \mathrm{mV}$. Single exponential fits to the onset of the pulse and the tail currents gave $\tau_{\text {act }}=0.85 \mathrm{msec}$ and $\tau_{\text {dact }}=0.63 \mathrm{msec}$ for the proximal recording and $\tau_{\text {act }}=4.20 \mathrm{msec}$ and $\tau_{\text {dact }}=2.20$ msec for the distal record. Current traces were filtered to $5 \mathrm{KHz}$ and were sampled at $50 \mu \mathrm{sec} /$ point.

acteristic form at command potentials above $I_{\mathrm{Ca}}$ threshold. At the onset of the voltage pulse, a transient outward current was recorded. This current has been reported in other cells under whole-cell patch-clamp and has been attributed to a gating current (e.g., Swandulla and Armstrong, 1988). The outward current was followed by a rapidly activating inward current that was sustained for the duration of the pulse. The rate at which the ion channels were activated was examined by fitting a single exponential (Fig. 5A) to the onset of the inward current, from the point at which the early outward current declined to 0 . The time constant of activation $\left(\tau_{\text {act }}\right)$ decreased with command voltage to a plateau level of $1.36 \pm 0.15 \mathrm{msec}($ mean $\pm \mathrm{SE})$ at +30 $\mathrm{mV}(N=5$ calyces; Fig. $5 B)$, with a minimum value of $0.9 \mathrm{msec}$ in 1 calyx. At low voltages, $\tau_{\text {act }}$ was more variable, in part as a result of the difficulty of fitting exponentials to small current amplitudes. At the end of the pulse, the Ca channels deactivated rapidly to give a brief tail current. A single exponential was fit to thc tails and had a timc constant $\left(\tau_{\text {dact }}\right)$ of $0.77 \pm 0.14 \mathrm{msec}$ at $-80 \mathrm{mV}(N=4$ calyces, $4-8 \mathrm{fits} / \mathrm{calyx})$, with a minimum of $0.5 \pm 0.04 \mathrm{msec}(N=8$ traces $)$ in 1 calyx.

On occasion, whole-cell current recordings were obtained with the electrode tip applied to the outer skirt of the calyx. Skirt $I_{\mathrm{Ca}} \mathrm{s}$ generally activated more gradually and had slower decaying tails (Fig. 5D), a difference that was attributed to the thinner intermembrane space in the remote regions of the calyx, resulting in an exacerbated space-clamp problem.

\section{Inactivation of calyx Ca currents}

Voltage-dependent inactivation is a biophysical characteristic of many ion channels and is evident either as a decay of the ion current during a voltage step or as "steady-state" inactivation, a decline in the amplitude of the current evoked by a voltage pulse to a fixed potential when the holding potential is depolarized.

It was noted previously that the $I_{\mathrm{Ca}}$ did not decay during a short 25-msec pulse (Stanley, 1989). Longer pulse durations of $80 \mathrm{msec}$ also failed to elicit a decay in the calyx $I_{\mathrm{Ca}}$ (Fig. 4). In addition, the calyx $\mathrm{Ca}$ channels did not exhibit prominent steadystate inactivation. Changing the holding potential from -80 to $-40 \mathrm{mV}$ resulted in only a moderate reduction in the $I_{\mathrm{Ca}}$ (to $58.7 \pm 6.5 \%$ with a step to $+30 \mathrm{mV} ; N=7$; Fig. 6). These results indicate that the calyx $\mathrm{Ca}$ channels are relatively resistant to voltage-dependent inactivation.

\section{Effect of cadmium on the $\mathrm{I}_{C a}$}

The effects of inorganic and pharmacological agents on the calyx $I_{\mathrm{Ca}}$ were tested by pressure ejection from a pipette during a train of command pulses. Cadmium ions, well-established $I_{\mathrm{Ca}}$ block- 

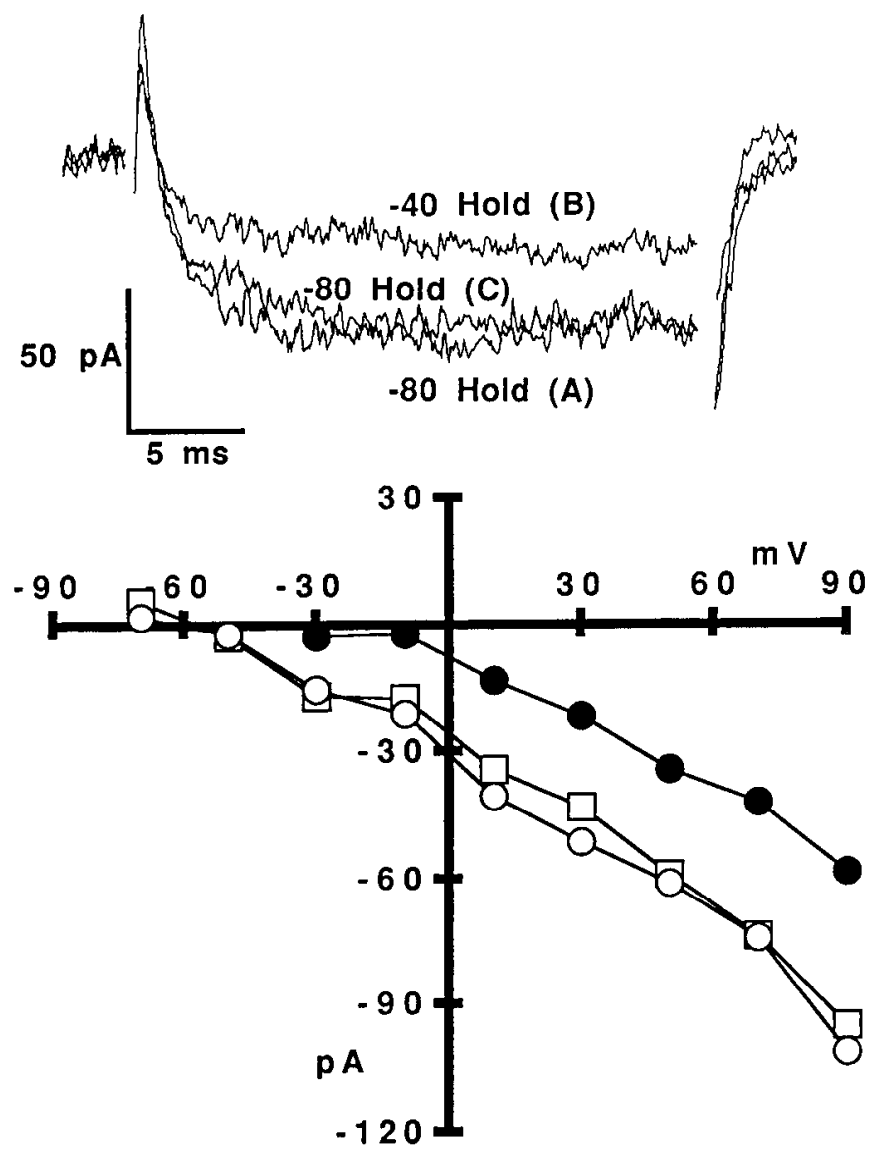

Figure 6. Steady-state inactivation of calyx $I_{\mathrm{Ca}}$. Top, Effect of changing the holding potential from -80 to $-40 \mathrm{mV}$ and back on calyx current traces stepped to $+50 \mathrm{mV}$ (in order of A to C). Data were filtered to 5 $\mathrm{KHz}$ and sampled in order at $50 \mu \mathrm{sec} /$ point. Current records were filtered digitally with a time constant of $0.1 \mathrm{msec}$ for display. Bottom, $I_{\mathrm{Ca}} / V$ relation with holding potentials sequentially at $-80 \mathrm{mV}(0),-40 \mathrm{mV}$ $(\bullet)$, and $-80 \mathrm{mV}(\square)$. Current amplitudes were measured over the last $7.5 \mathrm{msec}$ of each pulse.

ers, were introduced to the calyx while stepping the membrane potential to $+30 \mathrm{mV}$ from a holding potential of $-80 \mathrm{mV}$. The $I_{\mathrm{Ca}}$ was blocked at pipette Cd concentrations ranging from $1 \mathrm{~mm}$ down to $0.1 \mathrm{~mm}(N=8$; Fig. 7$)$. At $0.1 \mathrm{~mm} \mathrm{Cd}$, the degree of block ranged from $36 \%$ to $100 \%$ (mean, $76 \pm 13 \%$ ) in 5 calyces.

The calyx $I_{\mathrm{Ca}}$ was also blocked by $\omega$-CTX $(10 \mu \mathrm{M}$ to $10 \mathrm{nM}$; $N=6$; Fig. 8), but, in contrast to Cd block, the effect of the toxin was not rapidly reversible.

\section{Discussion}

The main findings of this study are, first, that it is possible to apply whole-cell voltage-clamp techniques to an intact vertebrate presynaptic nerve terminal. Second, inward currents can be recorded that can be attributed to the influx of $\mathrm{Ca}$ ions. Third, the recorded $I_{\mathrm{Ca}}$ has activation and deactivation properties consistent with a role in transmitter release. Finally, the properties of the calyx $\mathrm{Ca}$ channels are consistent with findings on nerve terminals using other techniques but do not fit readily into established schemes of Ca channel classification.

The ciliary ganglion calyx was examined at a particular point during development dictated by nerve terminal enlargement, the progression from chemical to electrical transmission (Hess et al., 1969; Landmesser and Pilar, 1972) and the feasibility of
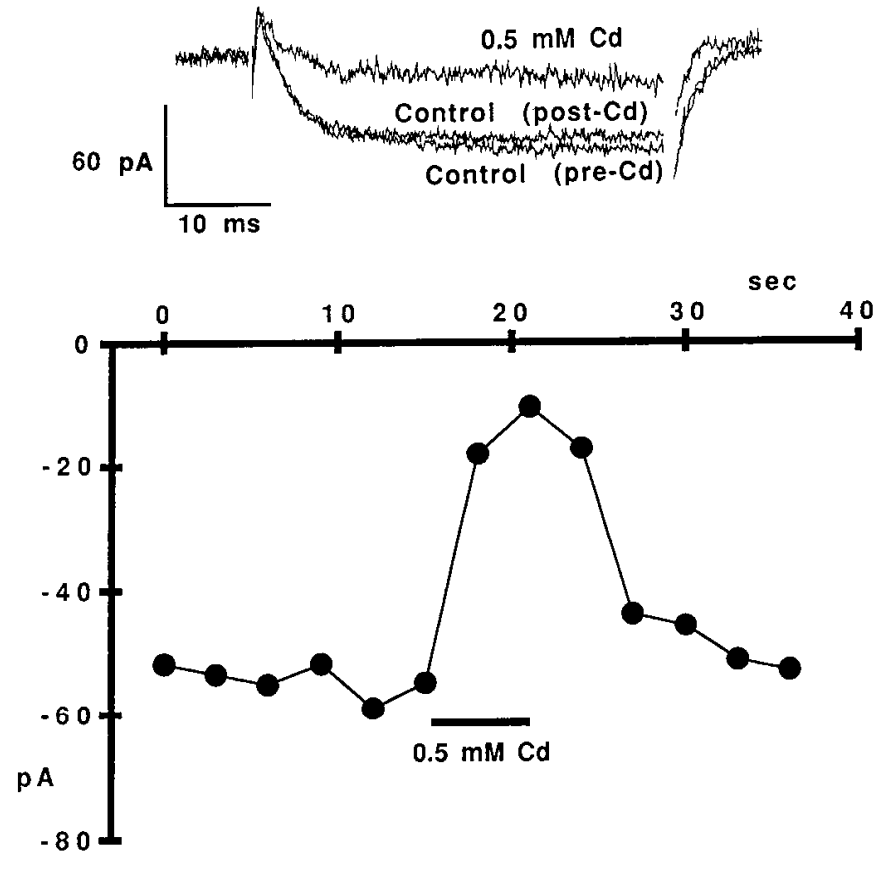

Figure 7. Block of calyx $I_{\mathrm{Ca}}$ by Cd ion. Top, Each trace is the average of 3 current records before, during, and after exposure to $0.5 \mathrm{~mm} \mathrm{Cd}$ dissolved in external buffer $(6 \mathrm{~mm} \mathrm{Ca})$ and ejected from a closely positioned pipette. The calyx was held at $-80 \mathrm{mV}$ and was stepped to $+30 \mathrm{mV}$. Data were filtered at $5 \mathrm{KHz}$ and sampled at $50 \mu \mathrm{sec} /$ point. Bottom, $I_{\mathrm{Co}}$ amplitude (over the last $7.5 \mathrm{msec}$ ) in sequential traces during exposure to $\mathrm{Cd}$.

dissociation. The calyx begins to form at about stage 36.5 , long after the onset of chemical transmission at stage 26.5. Dissociation and development of calyces for patch clamping was ideal at stage 40-41, prior to the development of significant electrical coupling at stage 42 (Landmesser and Pilar, 1972).

The ganglia were dissociated with specific enzymes (collagenase, hyaluronidase, and Dispase) while suppressing any contaminating tryptic activity. There were 2 steps to this dissociation: the separation of intact ciliary neuron capsules with the collagenase and the hyaluronidase, and the exposure of the calyces from the ensheathing Schwann cells with Dispase. The retraction of the Schwann cells is most likely due to the action of Dispase on type VI collagen (Stenn et al., 1989), an integral component of basal lamina.

The inward current recorded in the ciliary neurons and calyces can be attributed to the opening of Ca channels on the basis of the composition of the buffers, the presence of agents that block the other main cation channels (TTX, TEA), and the sensitivity to block by $\mathrm{Cd}$ and $\omega$-CTX. This current was recruited at about $-30 \mathrm{mV}$, consistent with a recent report in the lizard calyx (Martin et al., 1989) and probably involves a single species of ion channel. It is unlikely that the presynaptic $\mathrm{Ca}$ channels were affected by the enzyme treatment, in particular the Dispase. This enzyme does not have a broad spectrum of action but exhibits a specific proteolytic effect on fibronectin and type IV collagen (Stenn et al., 1989). Thus, very similar inward $I_{\mathrm{Ca}} \mathrm{s}$ were recorded in a few calyces that were isolated with collagenase alone. Furthermore, ciliary neurons isolated with Dispase exhibited complex $I_{\mathrm{Ca}}$ s that included at least 2 components (Stanley, 1989; E. Stanley, unpublished observations), typical of chick neurons (Fox et al., 1987a). 


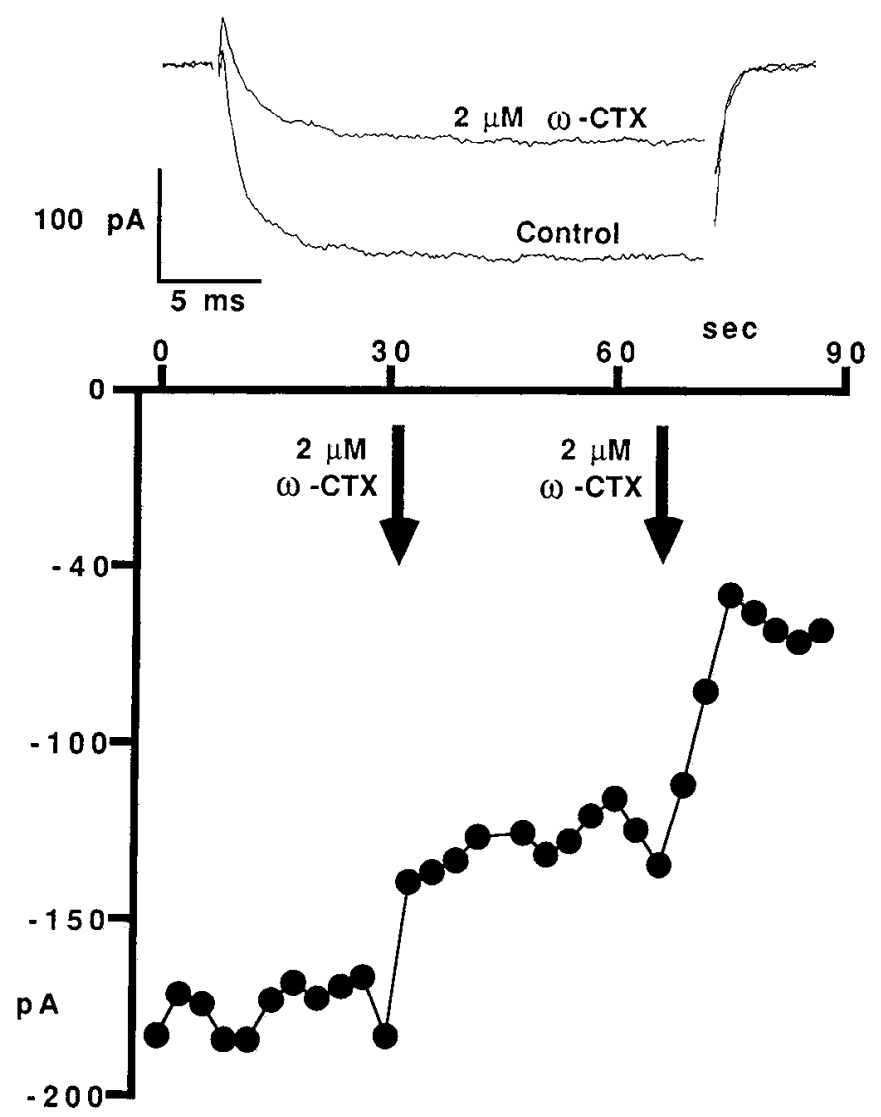

Figure 8. Block of calyx $I_{\mathrm{Ca}}$ by $\omega$-CTX. Top, Calyx $I_{\mathrm{Ca}}$ before and after 2 pulses of pressure-ejected $\omega$-CTX (see plot below). Each trace is an average of 4 current records evoked by a pulse to $+30 \mathrm{mV}$ from a holding potential of $-80 \mathrm{mV}$. Data were filtered at $2 \mathrm{KHz}$ and were sampled at $50 \mu \mathrm{sec} /$ point. Bottom, Time course of the effect of $2 \mu \mathrm{M}$ $\omega$-CTX on the amplitude of sequential current records during 2 puffs of pressure-ejected toxin.

The recording of ion currents in the calyx was complicated by the difficulty of achieving a symmetrical voltage clamp (Stanley, 1989). $I_{\mathrm{Ca}}$ s did not cscapc from the clamp because of the low current density, but it is likely that the clamp potential declines at increasing distances from the point of contact of the patch electrode (see model by Jack et al., 1975). Thus, Ca ion flux occurs through ion channels that are exposed to a membrane potential that ranges from the step potential to ion channel threshold. The monotonic current-voltage relation of the $I_{\mathrm{Ca}}$ was attributed to the depolarization to threshold of a larger membrane area and a recruitment of a greater fraction of the calyx Ca channels with each increment in the command potential.

The calyx Ca channels had properties that were consistent with chemical transmission at this synapse. Both the $I_{\mathrm{Ca}}$ and synaptic transmission were blocked by $\mathrm{Cd}$ and $\omega$-CTX and were insensitive to nifedipine (Atrakchi et al., 1990; Stanley and Atrakchi, 1990). The action potentials in this (Martin and Pilar, 1963a) and other fast-transmitting presynaptic nerve terminals are only of $1-1.5-\mathrm{msec}$ duration. In order for Ca entry to trigger transmitter secretion, the $\mathrm{Ca}$ channels must activate within this period. The activation of the calyx $I_{\mathrm{Ca}}$ was consistent with this time restriction. At a potential corresponding to the peak of the action potential, approximately $+30 \mathrm{mV}$, the $\tau_{\text {act }}$ of the calyx
$I_{\mathrm{Ca}}$ is $0.9-1.6$ msec. Thus, during an action potential, the $I_{\mathrm{Ca}}$ is activated to at least $2 / 3$ of its maximum.

It has been demonstrated that most of the $\mathrm{Ca}$ influx into the nerve terminal occurs during the repolarization phase of the action potential when the driving force for $\mathrm{Ca}$ entry is the greatest, that is, during the Ca tail current (Llinas et al., 1982). Thus, the duration of secretion is limited by the decay of the $\mathrm{Ca}$ tail current (Llinas, 1982). In order to terminate secretion abruptly and to transmit impulse trains at high frequencies, the $I_{\mathrm{Ca}}$ must deactivate rapidly. The recorded $\tau_{\mathrm{dact}}$ for the calyx $I_{\mathrm{Ca}}$ was as low as $0.5 \mathrm{msec}$, suggesting that the calyx $\mathrm{Ca}$ channels deactivate at very rapid rates, comparable to those recorded in the presynaptic terminal of the squid giant synapse (Llinas, 1984). Time constants measured in the calyces may be underestimated as a result of the inadequate space clamp. Thus, the actual Ca channel $\tau_{\text {act }}$ and $\tau_{\text {dact }}$ values may be even more rapid then determined in this study.

Ca channels have been characterized by the kinetic properties of the inward $I_{\mathrm{Ca}}$ recorded from the intact whole cell. This has led to the recognition of more than one $I_{\mathrm{Ca}}$ type (for review, see Bean, 1989). A classification that has proved popular in neurons is the distinction of $3 I_{\mathrm{Ca}} \mathrm{s}$, termed $\mathrm{T}$, L, and $\mathrm{N}$ (Nowycky et al., 1985; Fox et al., 1987a; but see Swandulla and Armstrong, 1988). These currents have been attributed to Ca ion movement through 3 corresponding ion channel types (Nowycky et al., 1985; Fox et al., 1987b). It is apparent, however, that this classification may be too simple to describe all neural $\mathrm{Ca}$ channels, in particular with regard to the N-type. Several studies report Ca channels that have conductances and dihydropyridine (DHP) sensitivities that are "N-like" (Bean, 1989) but, unlike the Ntype, show little voltage-dependent inactivation (Hirning et al., 1988; Aosaki and Kasai, 1989; Kongsamut et al., 1989; Plummer et al., 1989).

The calyx $\mathrm{Ca}$ channels did not exhibit prominent inactivation, either during the voltage pulse or in response to a depolarization of the holding potential from very negative values. While the space-clamp limitation raises some question as to the significance of these findings, it is difficult to imagine that the recruitment of remote unclamped currents could exactly balance current decay in all (over 60) calyces examined. Other properties of these channels include a threshold of about $-30 \mathrm{mV}$, very rapid activation and deactivation, and insensitivity to DHP blockers (Stanley and Atrakchi, 1990) but block by $\omega$-CTX. Together, these properties describe a combination that does not fit any of the above Ca channel categories. They are, however, consistent with previous studies on presynaptic nerve terminal Ca channels at many fast-transmitting synapses using more indirect techniques. These include insensitivity to DHP blockers (see Nachsen and Blaustein, 1979; Perney et al., 1986; Miller, 1987; Hirning et al., 1988; Suszkiw et al., 1989), slow inactivation (Suszkiw et al., 1986), and sensitivity to $\omega$-CTX (Kerr and Yoshikami, 1984; Yoshikami et al., 1989).

The calyx $I_{\mathrm{Ca}}$ is not identical to $I_{\mathrm{Ca}} \mathrm{s}$ recorded in any other nerve terminal. The absence of rapidly inactivating components is similar to the $I_{\mathrm{Ca}}$ of the presynaptic nerve terminal of the squid giant synapse (Augustine et al., 1989). It differs from the squid, however, in voltage threshold and sensitivity to $\omega$-CTX: the squid $I_{\mathrm{Ca}}$ activates at very negative potentials (I linas et al., 1981) and is insensitive to the toxin (Charlton and Augustine, 1987). In contrast, the posterior pituitary neurosecretosome, a hormone-secreting nerve terminal, has both inactivating and 
noninactivating $I_{\mathrm{Ca}}$ components (Lemos and Nowycky, 1989), as does the isolated growth cone of cultured frog sympathetic neurons (Thayer et al., 1987; Lipscombe et al., 1988).

The calyx Ca channel exhibits several similarities to the "Ntype" group but differs from most, if not all, of these with respect to voltage-dependent inactivation. This difference, together with the likelihood that the particular demands of presynaptic function will have led to the development of a unique typc of $\mathrm{Ca}$ channel, makes us reluctant to catalog this channel as $\mathrm{N}$-type. Further information, including an analysis of single channel properties, is required before reaching this conclusion. Thus, for the present, this channel is best designated $\mathrm{Ca}_{\mathrm{N}-\mathrm{PT}}$ (N-like, presynaptic nerve terminal). Presumably this, or other closelyrelated $\mathrm{Ca}$ channel types, links impulses to $\mathrm{Ca}$ entry at a variety of vertebrate fast-transmitting synapses.

\section{References}

Aosaki T, Kasai H (1989) Characterization of two kinds of highvoltage-activated Ca-channel currents in chick sensory neurons. Pfluegers Arch 414:150-156.

Atrakchi AH, Llinas R, Stanley EF (1990) Action of Ca channel blockers on synaptic transmission in the chick ciliary ganglion. Fed Proc 4:A1 199.

Augustine GJ, Buchanan J, Charlton MP, Rosses L, Smith SI (1989) Fingering the trigger for neurotransmitter secretion: studies on the calcium channels of squid giant presynaptic terminals. Soc Gen Physiol Ser 4:203-223.

Bean B (1989) Classes of calcium channels in vertebrate cells. Annu Rev Physiol 51:367-384.

Carpenter RW (1911) The ciliary ganglion of birds. Folia Neurol Biol 5:738-754.

Charlton MP, Augustine GJ (1987) Classification of presynaptic calcium channels in the squid giant synapse. Biol Bull 173:441-442.

de Lorenzo AJ (1960) The fine structure of synapses in the chick ciliary ganglion. J Biophys Biochem Cytol 7:31-36.

Dryer SE, Chiappinelli VA (1985) Substance P depolarizes nerve terminals in an autonomic ganglion. Brain Res 336:190-194.

Fox AP, Nowycky MC, Tsien RW (1987a) Kinetic and pharmacological properties distinguishing three types of calcium currents in chick sensory neurons. J Physiol (Lond) 394:149-172.

Fox AP, Nowycky MC, Tsien RW (1987b) Single-channel recordings of three types of calcium channels in chick sensory neurons. J Physiol (Lond) 394:173-200.

Hamburger V, Hamilton IIL (1951) A series of stages in the development of the chick embryo. J Morphol 88:49-92.

Hamill OP, Marty A, Neher E, Sakmann B, Sigworth FJ (1981) Improved patch clamp techniques for high resolution current recording from cells and cell-free patches. Pfluegers Arch 391:85-100.

Hess A (1965) Developmental changes in the structure of the synapse on the myelinated cell bodies of the chicken ciliary ganglion. J Cell Biol 25:1-19.

Hess A, Pilar G, Weakley JN (1969) Correlation between transmission and structure in avian ciliary ganglion synapses. J Physiol (Lond) 202: 339-354.

Hirning LD, Fox AF, McCleskey EW, Olivera BM, Thayer SA, Miller $\mathrm{RJ}$, Tsien RW (1988) Dominant role of N-type Ca channels in evoked release of norepinephrine from sympathetic neurons. Science 239:57-60.

Jack JJB, Noble D, Tsien RW (1975) Electrical current flow in excitable cells, pp 83-92. Oxford: Clarendon.

Kerr LM, Yoshikami D (1984) A venom peptide with a novel presynaptic blocking action. Nature 308:282-284.

Kongsamut S, Lipscombe D, Tsien RW (1989) The N-type Ca channel in frog sympathetic neurons and its role in $\alpha$-adrenergic modulation of transmitter release. Ann NY Acad Sci 560:312-333.

Landmesser L, Pilar G (1972) The onset and development of transmission in the chick ciliary ganglion. J Physiol (Lond) 222:691-713.
Lemos JR, Nowycky MC (1989) Two types of calcium channel coexist in peptide-releasing vertebrate nerve terminals. Neuron 2:1419-1426.

Lipscombe D, Madison DV, Poenie DV, Reuter H, Tsien RY, Tsien RW (1988) Spatial distribution of calcium channels and cytostolic calcium transients in growth cones and cell bodies of sympathetic neurons. Proc Natl Acad Sci USA 85:2398-2402.

Llinas RR (1982) Calcium in synaptic transmission. Sc Am 247:5665.

Llinas RR (1984) The squid giant synapse. Curr Top Membr Transport 22:519-546.

Llinas RR, Steinberg IZ, Walton K (1981) Presynaptic calcium currents in squid giant synapse. Biophys J 33:289-321.

Llinas RR, Sugimori M, Simon SM (1982) Transmission by presynaptic spike-like depolarization in the squid synapse. Proc Natl Acad Sci USA 79:2415-2419.

Lyman D, Mugnaini E (1980) The avian accessory oculomotor nucleus. Soc Neurosci Abstr 6:479.

Martin AR, Pilar G (1963a) Dual mode of synaptic transmission in the avian ciliary ganglion. J Physiol (Lond) 168:443-463.

Martin AR, Pilar G (1963b) Transmission through the ciliary ganglion of the chick. J Physiol (Lond) 168:464-475.

Martin AR, Patel V, Faille L, Mallart A (1989) Presynaptic calcium currents recorded from calcyform nerve terminals in the lizard ciliary ganglion. Neurosci Lett 105:14-18.

Miller RJ (1987) Multiple calcium channels and neuronal function. Science 235:46-52.

Nachsen DA, Blaustein MP (1979) The effects of some organic "calcium antagonists" on calcium influx in presynaptic nerve terminals. Mol Pharmacol 16:579-586.

Nowycky MC, Fox AP, Tsien RW (1985) Three types of neuronal calcium channel with different calcium agonist sensitivity. Nature 316:440-443.

Perney TM, Hirning LD, Leeman SE, Miller RJ (1986) Multiple calcium channels mediate neurotransmitter release from peripheral neurons. Proc Natl Acad Sci USA 83:6656-6659.

Plummer MR, Logothetis DE, Hess P (1989) Elementary properties and pharmacological sensitivities of calcium channels in mammalian peripheral neurons. Neuron 2:1453-1463.

Stanley EF (1987) Light microscopic visualization of the presynaptic nerve terminal calyx in dissociated chick ciliary ganglion neurons. Brain Res 421:367-369.

Stanley EF (1989) Calcium currents in a vertebrate presynaptic nerve terminal: the chick ciliary ganglion calyx. Brain Res 505:341-343.

Stanley EF, Atrakchi AH (1990) The calcium current in the presynaptic nerve terminal of the chick giant synapse is insensitive to the dihydropyridine nifedipine. Proc Natl Acad Sci USA 87:9683-9687.

Stanley EF, Goping G (1989) Preparation of the 'chick giant synapse' for electrophysiological recording: $\mathrm{Ca}$ currents in a vertebrate presynaptic nerve terminal. Proc Soc Neurosci 15:484.

Stenn KS, Link R, Moellmann G, Madri J, Kuklinska E (1989) Dispase, a neutral protease from Bacillus polymyxa, is a powerful fibronectinase and type IV collagenase. J Invest Dermatol 93:287-290.

Stewart WW (1981) Lucifer dyes-highly fluorescent dyes for biological tracing. Nature 292:17-21.

Suszkiw JB, O'Leary ME, Murawsky MM, Wang T (1986) Presynaptic calcium channels in rat cortical synaptosomes: fast kinetics of phasic calcium influx, channel inactivation, and relationship to nitrendipine receptors. J Neurosci 6:1349-1357.

Suszkiw JB, Murawsky MM, Shi M (1989) Further characterization of phasic calcium influx in rat cerebrocortical synaptosomes: inferences regarding calcium channel type(s) in nerve endings. J Neurochem 52:1260-1269.

Swandulla D, Armstrong CM (1988) Fast-deactivating calcium channels in chick sensory neurons. J Gen Physiol 92:197-218.

Szentagothai J (1964) The structure of the autonomic interneuronal synapse. Acta Neuroveg 26:338-359.

Thayer SA, Hirning LD, Miller RJ (1987) Distribution of multiple types of $\mathrm{Ca}^{2+}$ channels in rat sympathetic neurons in vitro. Mol Pharmacol 32:579-586.

Yoshikami D, Bagaboldo Z, Olivera BM (1989) The inhibitory effects of omega-conotoxins on Ca channels and synapses. Ann NY Acad Sci 560:230-248. 